\title{
Comparative evaluation of serum calcitonin gene related peptide level in patients with migraine headache with and without aura
}

\section{Mostafa Rezaee ( $\sim$ rezaim@sums.ac.ir)}

Shiraz University of Medical Sciences Faculty of Dentistry https://orcid.org/0000-0003-3202-8174

Nahid Ashja zadeh

Shiraz Medical School: Shiraz University of Medical Sciences

\section{Sadegh Izedi}

Shiraz Medical School: Shiraz University of Medical Sciences

\section{Farinaz Fakhri}

Shiraz University of Medical Sciences Faculty of Dentistry

Research article

Keywords: Calcitonin gene-related peptide, Migraine, Aura

Posted Date: February 10th, 2021

DOI: https://doi.org/10.21203/rs.3.rs-201874/v1

License: (a) (i) This work is licensed under a Creative Commons Attribution 4.0 International License. Read Full License 


\section{Abstract \\ Background}

During a migraine attack, trigeminal activation results in the release of calcitonin gene-related peptide (CGRP), which stimulates the release of inflammatory cytokines playing an important role in migraine. We analyze the serum level of CGRP between two groups of migrainous patients (with aura and without aura)

\section{Materials and Methods}

Thirty six migraine patients (included 18 patients with aura and 18 without aura) additionally 18 healthy volunteers consisted control group were selected from the clinic of Neurology, Shiraz University of Medical Sciences, Shiraz, Iran, between March 2020 and November 2020. The CGRP level were determined from the sera of patients with migraine and control subjects by enzyme-linked immunosorbent assay kits. Spearman's rank correlation coefficient was also determined to calculate the correlation between CGRP and clinical findings.

\section{Results}

The level of CGRP in groups were significantly different between groups $(P=0.00)$. Also, the level of CGRP in aura group were significantly higher than non-aura group $(P=0.045)$. The Spearman's correlation coefficient revealed a positive and significant correlation between the CGRP concentration and age $(p=$ $0.042, r=0.172)$, BMI $(p=0.013, r=0.08)$, VAS $(P=0.006, r=0.09)$, frequency of attacks $(p=0.005, r=0.9)$, duration of each attack $(p=0.016, r=0.23)$, Migraine Disability Assessment Scale. $(p=0.00, r=0.785)$, average of number of Medication ( $p=0.00, r=0.694)$. However, no significant correlation was observed with gender. $(P>0.05)$

\section{Conclusions}

In our study, we found migraine patients had a higher CGRP level than healthy controls and the level of CGRP was related significantly with the duration, BMI, frequency of headache, age, number of headaches per day. In conclusion, our results confirmed that CGRP may be involved in the pathogenesis of migraine attacks and related with the multiple clinical characteristics.

\section{Introduction}

Headache is among the most common reasons patients seek medical attention, on a global basis being responsible for more disability than any other neurologic problem. Diagnosis and management are based on a careful clinical approach augmented by an understanding of the anatomy, physiology, and 
pharmacology of the nervous system pathways mediating the various headache syndromes. (1) The first and most important consideration in evaluating patients with complaints of orofacial pain or headache is to rule out an underlying progressive structural lesion or systemic diseases, such as intracranial tumors, severe infection, aneurysms, hypertension, and stroke. Headache is generally a benign symptom, but it is estimated that $5 \%$ of patients with headache in emergency settings are found to have a serious underlying disorder, emphasizing the need for rapid and accurate diagnosis of headache.(2)

Migraine is a common disabling primary headache disorder. It is estimated that the prevalence of migraine headaches in adults with current headache disorder, at least once last year from symptoms is $47 \%$. Half to three-quarters of adults between the ages of 18 and 65 in the world had headaches last year, and more than 10 percent of them reported migraines (3). Migraines are common especially during adolescence, and in women of childbearing age but this is occurred as most prevalent childhood headache (4). An analysis from the 2016 Global Burden of Disease (GBD) study, including data from 132 countries, estimated that worldwide 1.04 billion people had migraine, corresponding to a prevalence of $14.4 \%$ overall, $18.9 \%$ in women, and $9.8 \%$ in men.(5) The core features of migraine are headache, which is usually throbbing and often unilateral, and associated features of nausea, sensitivity to light, sound, and exacerbation. Clinically, migraine is categorized into five categories include: Migraine without aura (common migraine), Migraine with aura (classic migraine), chronic migraine (CM), episodic migraine (EM) and probable migraine headaches. (6)

In common migraines or migraine without aura, there are no focal neurological symptoms before the headache. In migraine with aura, the headache is preceded by stereotyped sensory, motor, or visual symptoms. The most common premonitory symptoms in migraine include visual scotomas and fortification spectra, and approximately one third of all migraineurs are affected. (7) CM defined as experiencing more than 15 days of headache per month with at least 8 days with migraine characteristics or response to Triptans, for at least 3 months and episodic migraine (EM) defined as having less than 15 days of migraine headache per month (8). If EM patients do not receive proper treatment, their headaches can progress to CM over time. In comparison with EM sufferers, subjects with CM experience greater headache-related disability. (9) Migraine frequency varies considerably. In many patients, migraine is triggered by specific factors, such as menses, weather changes, irregular sleep, alcohol, or certain foods. Migraine is also often relieved by sleep.(10)

Many mechanisms and theories explaining the causes of migraine have been

proposed, although the full picture is still elusive. A strong familial association and the early onset of the disorder suggest a genetic component, which has led some to question whether it is a channelopathy. There appears to be a genetic and familial risk as more than half of all migraineurs report having other family members who suffer from migraine. In addition, specific mutations leading to rare causes of vascular headache have been identified. Some researchers suggests that variations within the dopamine D2 receptor gene also may have some effect on susceptibility to migraine. $(11,12)$ The trigeminal vascular model by Moskowitz explains that trigeminal activation resulting in the release of neuropeptides 
produces neurogenic inflammation, increased vascular permeability, and dilation of blood vessels.(13) Other pathophysiologic mechanisms behind migraine have been proposed, such as serotonin, calcitonin gene-related peptide, nitric oxide, dopamine, norepinephrine, glutamate, and other substances as well as mitochondrial dysfunction. (13-16) It has recently been recognized that central sensitization producing allodynia and hyperalgesia is an important clinical manifestation of migraine. $(17,18)$

The aura of migraine was once thought to be caused by cerebral vasoconstriction and the headache by reactive vasodilation, which explained the throbbing quality of migraine and the relief of pain by ergots. Some cerebral blood flow changes do occur in aura, however, migraine without aura demonstrates no flow abnormalities; thus, it is unlikely that simple vasoconstriction and vasodilation are the fundamental pathophysiologic feature. $(19,20)$

Recent studies have identified specific substances and receptors with potential roles in nociception that provide therapeutic targets, including substance P, calcitonin gene related peptide (CGRP), glutamate, serotonin, vanilloid receptor and NMDA receptor. (21) These neuropeptides and other cytokines interact with the blood vessel wall to produce dilation, plasma protein extravasation, and platelet activation producing a sterile inflammation that activates trigeminal nerve nociceptive afferents leading to further pain production.(22)

CGRP was first reported in 1982. This peptide are found in two types, alpha and beta. CGRP I or a-CGRP is a 37-amino acid neuropeptide and is formed from the alternative splicing of the calcitonin/CGRP gene located on chromosome 11. CGRP II or $\beta$-CGRP is less studied. In humans, $\beta$-CGRP differs from the $a-$ CGRP by three amino acids and is encoded in a separate gene within the same vicinity. CGRP has a distribution in both operation and receptor type, with 4 different receptor types reported for this peptide so far. This peptide can also act as a neurotransmitter, or a local hormone, or a neurodegenerator, which can have a variety of effects on different tissues (23).

CGRP levels increase in the cranial circulation during migraine attacks, and GRP injection in migraineurs results in migraine-like attacks. The somatosensory function of CGRP has been implicated in the development of neuronal sensitization and pain generation, most notably in migraine. Considerable evidence points towards CGRP as a key player in migraine pathogenesis: (a) CGRP is a potent vasodilator, and is present in afferents innervating meningeal blood vessels; (b) CGRP is a neurotransmitter that can enhance synaptic transmission mediated by glutamatergic signaling; (c) Elevations of CGRP can be detected in jugular venous blood during migraine attacks; (d) Intravenous injection of CGRP triggers migraine in patients with migraine, but not in healthy volunteers. (24-26)

The role of CGRP in migraine pathophysiology has gained considerable interest in recent years. This led to the development of small molecule CGRP receptor antagonists for acute and preventive treatment of migraine and monoclonal antibodies against CGRP mechanisms for migraine prevention. (27) Ziegler and Hassanein found that $44 \%$ of patients diagnosed as having migraine with aura reported having had an aura occur without a headache at some time.(28) Mattsson and Lundberg compared 100 women with migraines in a headache clinic in Sweden with 245 women in the general population and found that the 
lifetime prevalence of visual disturbances without a headache was $37 \%$ in those with migraines and $13 \%$ in the general population. Undoubtedly, some of those in the general population had migraines as well. (29) Peripherally administered CGRP induces spontaneous pain in mice. Brandon J. Rea et al report that peripherally administered CGRP can act in a light-independent manner to produce spontaneous pain in mice that is manifested as a facial grimace. As an objective validation of the orbital tightening action unit of the grimace response, we developed a squint assay using a video-based measurement of the eyelid fissure, which confirmed a significant squint response after CGRP injection, both in complete darkness and very bright light. (30) Despite many studies occurred about CGRP in migraine headaches, the exact pathways involved in CGRP-induced migraine attacks and mechanisms of action of CGRP antagonists are largely unknown (31). According to our researches, evaluation and comparison between migrainous group according to aura and their clinical variation such as severity, duration, frequency of attacks, weight, didn't published.

The present study aim to investigate serum CGRP level in participants of three groups of this study: healthy control, migraine with aura and migraine without aura by using ELISA methods and also define its concentration in relation to clinical and features.

\section{Material And Methods}

The subjects in groups will be selected following an advertisement asking for voluntary participation in a case-control study on the serum evaluation in migraine. Recruitment will be done during 3 months. Migraine with aura and migraine without aura patients will be enrolled as the case groups and headachefree individuals will be enrolled as controls. The case subjects will be recruited from the Emam Reza Clinic and Shahid Motahari Clinic (Shiraz, Iran) and the controls will be selected from healthy age-sex matched headache-free volunteers from the general population. According to previous studies $(32,33)$, our sample size will be consisted minimum 40 patients in each groups. The diagnosis of migraine will be made following an examination by an expert headache specialist-neurologist according to the International Headache Society Criteria (ICHD-III). Patients having episodic or chronic migraine for at least six months preceding study entry were selected. The inclusion criteria for enrollment in the present study will be as follows: being in the age range between 18 and 45 years old; having a body mass index (BMI) between 18.5 and $35 \mathrm{~kg} / \mathrm{m}^{2}$; not suffering from medication overuse headache $(\mathrm{MOH})$; not having a medical history of inflammatory, infectious, allergic or immune disorders; not having a history of cardiovascular or endocrinological diseases, liver or kidney disorders, or other neurological or chronic diseases such as epilepsy, Parkinson's disease, multiple sclerosis, or Alzheimer's disease. Exclusion criteria will be consist of: subjects had a history of the above-mentioned disorders or not willing to sign the informed consent form or they don't need blood test checkup.

At the initial visit, the required information regarding demographic and anthropometric data, medical history, and medications consumed will be obtained. This information will be include: gender, age, duration, body mass index (BMI), frequency of headaches, pain severity (VAS), the number of headache days, and the number of abortive medications and type of them. 
After the examination of migraine patients by the headache specialist-neurologist, the diagnosis of the type of migraine will be confirmed. The patients then will instructed on how to fill out a headache diary (designed by senior researcher Prof. Talebpour (34)). Over the following month. All patients will be followed via weekly telephone calls throughout this month. Using these headache diaries, information on headache features such as the number of headache days, mean severity of headaches according to Visual Analog Scale (VAS), and the number of abortive medications taken will be collected. The mean severity of headaches was measured; using the visual analog scale (VAS) scoring system which rates the intensity of pain with a score ranging from 0 (almost having no pain) to 10 (the worst possible pain experienced by the subject).

Five $\mathrm{ml}$ venous blood sample of each participants were gathered at same time under resting condition and trained laboratory technician. Collection of blood samples was performed with commercially available ethylenediamin- etetraacetic acid (EDTA) blood collection tubes (Greiner Bio-One GmbH, Kremsmunster, Austria) before surgery. Serum was separated from clotted blood after centrifugation at $4^{\circ} \mathrm{C}$ and stored at $-70^{\circ} \mathrm{C}$ for future assay. Sampling was done by expert laboratory technician. Evaluation of serum CGRP level in this study was done by sandwich technique by the CGRP ELISA Kit (Cat.No: MBS020873, Myobiosource, USA) for measurement according to the manufacturer's instructions. The ELISA kit contains 96 vials containing a monoclonal antibody against calprotectin in each vial, and each vial is used to examine a patient's serum. By determining the wavelength of each of the standard samples, a graph can be prepared. Since there is a direct relationship between the amount of calprotectin and the amount of dye produced, this amount of dye produced by ELISA READER is measured.

The data were statistically analyzed using SPSS Statistical software (version 18.0 for windows; SPSS Chicago, IL, USA). In order to test the normality distribution of data, a Kolmogorov-Smirnov test will be applied. A P value of $<0.05$ will considered the statistical significance level in all performed analyses. The chi square test will used to compare the distribution of categorical variables between case and control groups and the independent-sample t-test will be performed to examine normal distribution of continuous variables. Analysis of variance (ANOVA) and the Bonferroni post-hoc t-test will be used to make comparisons between the two groups of migraine patients and controls for mean values of serum CGRP levels. The Pearson correlation test will applied in order to discover the correlations between quantitative variables and CGRP level status in the migraine patient groups and the correlation coefficients will be reported.

\section{Results}

Fifty four participants in our study consisted 21 male patients (38.9\%) and 33 female patients (61.1\%). Thirty six migrainous patients included 18 migraine with aura and 18 migraine without aura, additionally 18 healthy volunteers were constituted the study groups. The descriptive data of participants and their distribution in this study report in Table 4-1. and Table 4-2. No significant differences observed between three groups according to age distribution ( $p$ value $=0.07$ ) gender distribution ( $p$ value $=0.064$ ). 
The mean \pm standard deviation of age of participants and range of age (maximum and minimum) of each groups of our study, reported in Table 4-3. No significant differences observed according to comparison between groups by Kruskal Wallis test. $(p=0.553)$

The mean \pm standard deviation of BMI of participants and range of BMI (maximum and minimum) of each groups of our study, reported in Table 4-4. No significant differences observed according to comparison between groups by Kruskal Wallis test. $(p=0.952)$

The characteristics of both migrainous groups present in Table 4-5. No significant differences observed according to comparison between groups by Kruskal Wallis test. ( $p>0.05)$ In our study, 28 of 36 migrainous patients used NSAIDS (Ibuprofen, Naproxen, Diclofenac), 25 patients used Acetaminophen / Acetaminophen codeine, 20 patients used Triptans, 14 patients used beta-blockers, 16 patients used anticonvulsant drugs (topiramate, sodium valproate), and 15 patients used tricyclic antidepressants.

The mean \pm SD of serum CGRP concentration and comparison between groups reported in Table 4-6. Apparent and significant differences observed according to comparison between groups by one way ANOVA test. $(p=0.00)$ The post Hoc test show that the serum CGRP concentration in migraine with aura group was higher than migraine without aura and control group. $(p=0.035)$ (Table 4-7.) Independent t test used for binary comparisons between groups and subgroups evaluation. The result of these evaluation present in Table 4-8. , Table 4-9. and Table 4-10. The mean of serum concentration of CGRP in migraine with aura is higher than control group (mean difference was $7.18 \mathrm{pg} / \mathrm{mL}$ ( $95 \%$ confidence interval [Cl]: 4.89, 7.87; $\mathrm{p}=0.00$ ). Also was higher than migraine without aura groups (mean difference was $0.850 \mathrm{pg} / \mathrm{mL}$ (95\% confidence interval [Cl]: $-2.15,0.823 ; p=0.045)$. The mean of serum concentration of CGRP in migraine without aura is higher than control group (Mean difference was $6.35 \mathrm{pg} / \mathrm{mL}$ (95\% confidence interval [Cl]: 5.48, 8.89; $\mathrm{p}=0.00$ ). Table 4-8. Binary comparison between migraine without aura group and control group according to CGRP serum level by independent $t$ test. Table 4-9. Binary comparison between migraine without aura group and migraine with aura group according to CGRP serum level by independent $t$ test. Table 4-10. Binary comparison between migraine with aura group and control group according to CGRP serum level by independent $t$ test.

The Spearman's correlation coefficient revealed a positive and significant correlation between the CGRP concentration and age $(p=0.042, r=0.172), B M I(p=0.013, r=0.08)$, VAS $(P=0.006, r=0.09)$, frequency of attacks $(p=0.005, r=0.9)$, duration of each attack $(p=0.016, r=0.23)$, Migraine Disability Assessment Scale. $(p=0.00, r=0.785)$. Also a negative and significant correlation between CGRP concentration and average number of used medication in patients observed $(p=0.00, r=-0.694)$. However, no significant correlation was observed with gender. $(P>0.05)$

\section{Discussion}

In some $20-30 \%$ of the migraineurs, the headache is preceded by a complex of focal neurological symptoms known as aura. Based on the presence or absence of aura symptoms, migraine is formally 
classified as: (i) migraine with aura (classical migraine), and (ii) migraine without aura (common migraine; more commonly seen). Migraine headache usually occurs in the early morning, typically lasts for $4-72 \mathrm{~h}$ and it has a striking feature of freedom from headache between the attacks. (35)

Generally, several factors have been known as the creators of migraine headaches, including emotional factors, environmental factors, and biochemical markers. Over the last 20 years major advances have occurred in our understanding of the role of calcitonin gene related peptide (CGRP) in the pathophysiology of migraine.

Rosenfeld et al. (36) demonstrated CGRP in the rat trigeminal ganglia and Mason et al. (37) reported in vitro calcium-dependent CGRP release from trigeminal ganglia upon depolarization. A dense supply of CGRP containing fibers around the cerebral vessels was reported to originate in the trigeminal ganglion. In 1988 Goadsby et al. reported that thermocoagulation of the trigeminal ganglion leads to CGRP release into the extra cerebral circulation of humans. This was the first report of CGRP involvement in the trigeminovascular reflex. Calcitonin gene related peptide is a potent vasodilator and a neuromodulator of nociceptive signaling and neurogenic inflammation. (38) Recober $A$ et al have previously reported that mice avoid light after either central or peripheral administration of CGRP. (39)

In the current study on populations of aura and non-aura migrainous patients and healthy controls, serum levels of CGRP were investigated. Further, in order to evaluate CGRP status, correlation with some clinical features such as age, severity, frequency, duration of attacks, number of used medications were explored.

In our study, the mean serum level of CGRP in control group was $13.97 \pm 2.19(\mathrm{pg} / \mathrm{mL})$. The CGRP level obtained $21.25 \pm 2.81(\mathrm{pg} / \mathrm{mL})$ in migraine with aura and $20.31 \pm 2.68(\mathrm{ng} / \mathrm{mL})$ in migraine without aura. We found that the CGRP were higher in migraine groups than control group. This finding is consistent with previous studies reported significantly higher CGRP levels in patients with migraine versus healthy control such as Sara Pérez-Pereda et al. (40), Reza Fekrazad et al. (41), Fusayasu et al (42) and Eva Cernuda-Morollón et al (43). However, Mi Ji Lee et al (44) and Jesper Filtenborg Tvedskov et al (45)reported in contrast our result, the CGRP level in migrainous patients have no significant difference with control groups. Trigeminal activation may lead to the release of CGRP into the cranial circulation, both in humans and in animal models. Several primary headaches, such as migraine, cluster and chronic paroxysmal hemicranias are associated with an increase in the CGRP level in the external and/or internal jugular vein during a pain attack.

In current study, we focused on the CGRP concentration according to aura status on the patients, the serum level of CGRP in migraine with aura patients was higher than non-aura group. Our results are is consisted with V Gallai et al (46). The importance of CGRP in migraine became firmly established when infusion of CGRP caused migraine-like attacks in patients with migraine without aura (MO) and CGRPreceptor antagonism was established as an effective treatment of migraine attacks. (47) Increased CGRP in external jugular venous blood during migraine attack is one of the most cited findings in the headache literature.(45) Clinically, elevated levels of CGRP have been reported in the cerebrospinal fluid (48), serum (49), and saliva (50) of migraineurs experiencing a headache, and serum levels were normalized after 
treatment. In recent years, many have shown that patients who suffer from migraine with aura are believed to have abnormal neurotransmitters reactivity in the CNS.(61)

We also considered clinical parameters such as gender, age, BMI, VAS, frequency and duration of headache attacks, average number of used medication and MIDAS score of each migrainous patients. In the present study, the CGRP level was measured only in the headache free period and limited to middle aged patients with female dominance. Our results revealed a positive and significant correlation between the CGRP concentration and age, BMI, VAS, frequency of attacks, duration of each attack, Migraine Disability Assessment Scale. Also a negative and significant correlation between CGRP concentration and average number of used medication in patients observed. However, no significant correlation observed with gender.

Regarding the relationship between migraine and age, it has been stated that there is an alternating prevalence of migraine and symptoms throughout the life span with some patients demonstrating a remission of the disease while others present a progression. Likewise, we only observed a very weak positive correlation was observed between age and CGRP levels in serum. This is in line with the findings of Cernuda-Morollón et al. (43), Sara Pérez-Pereda et al. (61), Reza Fekrazad et al. (62), Fusayasu et al (49) and who also choose chronic migraine patients with a mean age similar to the present study.

While patients with analgesic overuse (defined as using simple over-the-counter analgesics on more than 15 days per month) were excluded, medication usage by the patients on the days before sampling not be ruled out in this study. Therefore a negative correlation between averages numbers of used medication and CGRP, observed in our study. Although this may have influenced the results. Previous studies explored that analgesic use has been shown to reduce CGRP readings in serum, there may have been an even greater difference between migraine patients.

Multiple studies have confirmed that release of CGRP is increased during acute migraine attacks. As mentioned above, migraine headache is closely associated with the activation of the trigeminovascular system. Hence, stimulation of trigeminal ganglia/sensory nerves in several species (including humans) leads to the release of CGRP, which dilates cranial blood vessels and stimulates sensory nerve transmission. Moreover, CGRP-like immunoreactivity is abundantly expressed in trigeminal nuclei as well as in non-myelinated trigeminal sensory nerve fibers. Thus, it is clear that the cerebral vasculature is preferentially innervated by CGRP-containing sensory nerves. (51) Recent investigations have shown that nitric oxide, a potent vasodilator implicated in migraine headache, has a strong correlation with CGRP. Furthermore, i.v. infusion of nitric oxide produces a migraine-like headache with an associated increase in plasma CGRP levels.

\section{Conclusion}

In conclusion, according to the results of the present study and other mentioned studies, the mean CGRP levels in migraine patients are significantly higher than in normal people, and this demonstrates the role 
of CGRP in occurring migraine attacks. In our study, the highest relationship was between high CGRP level and frequency of headaches.

\section{References}

1. Dowell T, Martin PR, Waters AM. Headache and Migraine. Handbook of Childhood Psychopathology and Developmental Disabilities Treatment: Springer; 2017. p. 321-40.

2. Parker C, Gentile JL, Hendricks BL, Crane RA, Seiden AM. Headache and Facial Pain. Sataloff's Comprehensive Textbook of Otolaryngology: Head \& Neck Surgery: Pediatric Otolaryngology. 2015;6:331.

3. Younger DSJNc. Epidemiology of migraine. 2016;34(4):849-61.

4. Rao PM, Ailani JJJoCOM. Diagnosis and Treatment of Migraine. 2017;24(11).

5. Stovner LJ, Nichols E, Steiner TJ, Abd-Allah F, Abdelalim A, Al-Raddadi RM, et al. Global, regional, and national burden of migraine and tension-type headache, 1990-2016: a systematic analysis for the Global Burden of Disease Study 2016. The Lancet Neurology. 2018;17(11):954-76.

6. Society HCCotlH. The international classification of headache disorders, (beta version). Cephalalgia journal. 2013;33(9):629-808.

7. Russell M, Rasmussen B, Fenger K, Olesen JJC. Migraine without aura and migraine with aura are distinct clinical entities: a study of four hundred and eighty-four male and female migraineurs from the general population. 1996;16(4):239-45.

8. Ghorbani Z, Togha M, Rafiee P, Ahmadi ZS, Magham RR, Haghighi S, et al. Vitamin D in migraine headache: a comprehensive review on literature. 2019:1-19.

9. Carod-Artal FJJJopr. Tackling chronic migraine: current perspectives. 2014;7:185.

10. Martin PR. Triggers of Primary Headaches: Issues and Pathways Forward. Headache: The Journal of Head and Face Pain. 2020.

11. Palmas MA, Cherchi A, Stochino E, Congiu D, Del Zompo M. Dopamine genes and migraine. The Journal of Headache and Pain. 2000;1(2):S153-S6.

12. Ghosh J, Pradhan S, Mittal B. Identification of a novel ANKK1 and other dopaminergic (DRD2 and DBH) gene variants in migraine susceptibility. Neuromolecular medicine. 2013;15(1):61-73.

13. Goadsby P, Charbit A, Andreou A, Akerman S, Holland P. Neurobiology of migraine. Neuroscience. 2009;161(2):327-41.

14. Viola S, Viola P, Litterio P, Buongarzone MP, Fiorelli L. Pathophysiology of migraine attack with prolonged aura revealed by transcranial Doppler and near infrared spectroscopy. Neurological Sciences. 2010;31(1):165-6.

15. Chhater S, Karal R, Kumar BJAJBR. Review on migraine: pathophysiology and treatment. 2018;6(1):20-4.

16. Sparaco M, Feleppa M, Lipton RB, Rapoport A, Bigal M. Mitochondrial dysfunction and migraine: evidence and hypotheses. Cephalalgia. 2006;26(4):361-72. 
17. Dodick D, Silberstein S. Central sensitization theory of migraine: clinical implications. Headache: The Journal of Head and Face Pain. 2006;46:S182-S91.

18. Messlinger K. Migraine: where and how does the pain originate? Experimental brain research. 2009;196(1):179-93.

19. Hadjikhani N, Sanchez Del Rio M, Wu O, Schwartz D, Bakker D, Fischl B, et al. Mechanisms of migraine aura revealed by functional MRI in human visual cortex. Proc Natl Acad Sci U S A. 2001;98(8):4687-92.

20. Dalkara T, Nozari A, Moskowitz MA. Migraine aura pathophysiology: the role of blood vessels and microembolisation. The Lancet Neurology. 2010;9(3):309-17.

21. Aggarwal M, Puri V, Puri S. Serotonin and CGRP in migraine. Ann Neurosci. 2012;19(2):88.

22. Dodick DWJHTJoH, Pain F. A phase-by-phase review of migraine pathophysiology. 2018;58:4-16.

23. Deen M, Correnti E, Kamm K, Kelderman T, Papetti L, Rubio-Beltrán E, et al. Blocking CGRP in migraine patients-a review of pros and cons. 2017;18(1):96.

24. Tepper SJ. History and Review of anti-Calcitonin Gene-Related Peptide (CGRP) Therapies: From Translational Research to Treatment. Headache: The Journal of Head and Face Pain. 2018;58(S3):238-75.

25. Goadsby PJ, Holland PR, Martins-Oliveira M, Hoffmann J, Schankin C, Akerman S. Pathophysiology of Migraine: A Disorder of Sensory Processing. Physiological Reviews. 2017;97(2):553-622.

26. Khan S, Olesen A, Ashina M. CGRP, a target for preventive therapy in migraine and cluster headache: Systematic review of clinical data. Cephalalgia. 2017;39(3):374-89.

27. Villalón CM, Olesen J. The role of CGRP in the pathophysiology of migraine and efficacy of CGRP receptor antagonists as acute antimigraine drugs. Pharmacology \& therapeutics. 2009;124(3):30923.

28. Ziegler DK, Hassanein RS. Specific headache phenomena: their frequency and coincidence. Headache: The Journal of Head and Face Pain. 1990;30(3):152-6.

29. Mattsson P, Lundberg P. Characteristics and prevalence of transient visual disturbances indicative of migraine visual aura. Cephalalgia. 1999;19(5):479-84.

30. Rea BJ, Wattiez A-S, Waite JS, Castonguay WC, Schmidt CM, Fairbanks AM, et al. Peripherally administered CGRP induces spontaneous pain in mice: Implications for migraine. Pain. 2018;159(11):2306.

31. Khan S, Olesen A, Ashina MJC. CGRP, a target for preventive therapy in migraine and cluster headache: systematic review of clinical data. 2019;39(3):374-89.

32. Yücel M, Kotan D, Gurol Çiftçi G, Çiftçi I, Cikriklar HJERMPS. Serum levels of endocan, claudin- 5 and cytokines in migraine. 2016;20(5):930-6.

33. Togha M, Jahromi SR, Ghorbani Z, Ghaemi A, Rafiee PJBn. An investigation of oxidant/antioxidant balance in patients with migraine: a case-control study. 2019;19(1):323. 
34. Jahromi SR, Abolhasani M, Ghorbani Z, Sadre-Jahani S, Alizadeh Z, Talebpour M, et al. Bariatric surgery promising in migraine control: a controlled trial on weight loss and its effect on migraine headache. 2018;28(1):87-96.

35. Olesen J, Diener H-C, Husstedt IW, Goadsby PJ, Hall D, Meier U, et al. Calcitonin gene-related peptide receptor antagonist BIBN 4096 BS for the acute treatment of migraine. 2004;350(11):1104-10.

36. Rosenfeld MG, Mermod J-J, Amara SG, Swanson LW, Sawchenko PE, Rivier J, et al. Production of a novel neuropeptide encoded by the calcitonin gene via tissue-specific RNA processing. Nature. 1983;304(5922):129-35.

37. Mason RT, Peterfreund RA, Sawchenko PE, Corrigan AZ, Rivier JE, Vale WW. Release of the predicted calcitonin gene-related peptide from cultured rat trigeminal ganglion cells. Nature. 1984;308(5960):653-5.

38. Goadsby P, Edvinsson L, Ekman R. Release of vasoactive peptides in the extracerebral circulation of humans and the cat during activation of the trigeminovascular system. Annals of Neurology: Official Journal of the American Neurological Association and the Child Neurology Society. 1988;23(2):1936.

39. Recober A, Kuburas A, Zhang Z, Wemmie JA, Anderson MG, Russo AF. Role of calcitonin gene-related peptide in light-aversive behavior: implications for migraine. Journal of Neuroscience. 2009;29(27):8798-804.

40. Pérez-Pereda S, Toriello-Suárez M, Ocejo-Vinyals G, Guiral-Foz S, Castillo-Obeso J, Montes-Gómez S, et al. Serum CGRP, VIP, and PACAP usefulness in migraine: a case-control study in chronic migraine patients in real clinical practice. Molecular Biology Reports. 2020;47(9):7125-38.

41. Fekrazad R, Sardarian A, Azma K, Karami M, Borhani-Haghighi A, Gharesi-Fard B, et al. Interictal levels of calcitonin gene related peptide in gingival crevicular fluid of chronic migraine patients. Neurological Sciences. 2018;39(7):1217-23.

42. Fusayasu E, Kowa $H$, Takeshima T, Nakaso K, Nakashima K. Increased plasma substance $P$ and CGRP levels, and high ACE activity in migraineurs during headache-free periods. Pain. 2007;128(3):209-14.

43. Cernuda-Morollón E, Larrosa D, Ramón C, Vega J, Martínez-Camblor P, Pascual J. Interictal increase of CGRP levels in peripheral blood as a biomarker for chronic migraine. Neurology. 2013;81(14):1191-6.

44. Lee MJ, Lee S-Y, Cho S, Kang E-S, Chung C-S. Feasibility of serum CGRP measurement as a biomarker of chronic migraine: a critical reappraisal. The Journal of Headache and Pain. 2018;19(1):53.

45. Tvedskov JF, Lipka K, Ashina M, Iversen HK, Schifter S, Olesen J. No increase of calcitonin generelated peptide in jugular blood during migraine. Annals of Neurology. 2005;58(4):561-8.

46. Gallai V, Sarchielli P, Floridi A, Franceschini M, Codini M, Glioti G, et al. Vasoactive peptide levels in the plasma of young migraine patients with and without aura assessed both interictally and ictally. Cephalalgia. 1995;15(5):384-90. 
47. Ho T, Mannix L, Fan X, Assaid C, Furtek C, Jones C, et al. Randomized controlled trial of an oral CGRP receptor antagonist, MK-0974, in acute treatment of migraine. Neurology. 2008;70(16):1304-12.

48. van Dongen RM, Zielman R, Noga M, Dekkers OM, Hankemeier T, van den Maagdenberg AM, et al. Migraine biomarkers in cerebrospinal fluid: a systematic review and meta-analysis. Cephalalgia. 2017;37(1):49-63.

49. Tarperi C, Sanchis-Gomar F, Montagnana M, Danese E, Salvagno GL, Gelati M, et al. Effects of endurance exercise on serum concentration of calcitonin gene-related peptide (CGRP): a potential link between exercise intensity and headache. Clinical Chemistry and Laboratory Medicine (CCLM). 2020;1(ahead-of-print).

50. Bellamy JL, Cady RK, Durham PL. Salivary levels of CGRP and VIP in rhinosinusitis and migraine patients. Headache: The Journal of Head and Face Pain. 2006;46(1):24-33.

51. Arulmani U, MaassenVanDenBrink A, Villalón CM, Saxena PR. Calcitonin gene-related peptide and its role in migraine pathophysiology. European Journal of Pharmacology. 2004;500(1):315-30.

\section{Tables}

Table 4-1. Gender distribution of participant of this study

\begin{tabular}{|llllll|}
\hline Groups & \multicolumn{3}{l}{ Gender } & & P value \\
\cline { 3 - 5 } & & Male & Female & Total & \multirow{2}{*}{0.07} \\
\cline { 3 - 5 } Control & Num (\%) & $8(14.8)$ & $10(18.51)$ & $18(33.3)$ & \\
\cline { 1 - 5 } Migraine without aura & Num (\%) & $9(16.6)$ & $9(16.6)$ & $18(33.3)$ & \\
\cline { 1 - 5 } Migraine with aura & Num (\%) & $6(11.1)$ & $12(22.2)$ & $18(33.3)$ & \\
\hline Total & Num (\%) & $21(38.8)$ & $33(61.1)$ & $54(100)$ \\
\hline
\end{tabular}

Table 4-2. Age distribution of participant of this study

\begin{tabular}{|llllll|}
\hline Groups & Age & \multicolumn{3}{c}{ Mean rank } & P value \\
\cline { 2 - 4 } & Mean \pm SD & $\min$ & $\max$ & & \multirow{2}{*}{0.553} \\
\cline { 1 - 4 } Control & $36.91 \pm 4.1$ & 29 & 48 & 31.44 & \\
\cline { 1 - 4 } Migraine without aura & $39.55 \pm 3.75$ & 27 & 51 & 30.28 & \\
\hline Migraine with aura & $37.65 \pm 4.85$ & 33 & 46 & 29.72 \\
\hline
\end{tabular}


Table 4-3. The mean and standard deviation (SD) and range of participant age

\begin{tabular}{|lllllll|}
\hline Groups & & \multicolumn{2}{c}{ Age } & & P value \\
\cline { 3 - 6 } & & $25-35$ & $35-45$ & $45-55$ & Total & 0.064 \\
\cline { 1 - 6 } Control & Num (\%) & $3(5.5)$ & $9(16.6)$ & $6(11.1)$ & $18(33.3)$ & \\
\cline { 1 - 6 } Migraine without aura & Num (\%) & $5(9.25)$ & $10(18.5)$ & $3(5.5)$ & $18(33.3)$ & \\
\cline { 1 - 6 } Migraine with aura & Num (\%) & $6(11.1)$ & $8(14.8)$ & $4(7.4)$ & $18(33.3)$ & \\
\hline Total & Num (\%) & $14(25.9)$ & $27(50)$ & $13(24)$ & $54(100)$ & \\
\hline
\end{tabular}

Table 4-4. The mean and standard deviation (SD) and range of participant BMI

\begin{tabular}{|c|c|c|c|c|c|}
\hline \multirow[t]{2}{*}{ Groups } & \multicolumn{3}{|l|}{$\mathrm{BMI}$} & \multirow[t]{2}{*}{ Mean rank } & $P$ value \\
\hline & Mean \pm SD & $\min$ & $\max$ & & \multirow{4}{*}{0.952} \\
\hline Control & $28.41 \pm 1.16$ & 29 & 48 & 27.9 & \\
\hline Migraine without aura & $28.15 \pm 1.78$ & 27 & 51 & 26.54 & \\
\hline Migraine with aura & $27.35 \pm 1.65$ & 33 & 46 & 28.62 & \\
\hline
\end{tabular}

Table 4-5. Comparison of headache characteristics between migrainous groups

\begin{tabular}{|lll|}
\hline Groups & CGRP level $(\mathrm{pg} / \mathrm{mL})$ & P value \\
\hline Control & $13.97 \pm 2.19$ & \multirow{2}{*}{0.000} \\
\cline { 1 - 2 } Migraine without aura & $20.31 \pm 2.68$ & \\
\cline { 1 - 2 } Migraine with aura & $21.25 \pm 2.81$ & \\
\hline
\end{tabular}

Table 4-6. The serum CGRP concentration comparison between groups 


\begin{tabular}{|c|c|c|c|c|c|}
\hline groups & $\begin{array}{l}\text { Severity of } \\
\text { each } \\
\text { attack } \\
\text { (VAS) }\end{array}$ & $\begin{array}{l}\text { Frequency } \\
\text { of attacks } \\
\text { (per } \\
\text { month) }\end{array}$ & $\begin{array}{l}\text { Duration of } \\
\text { each attack } \\
\text { (hours) }\end{array}$ & $\begin{array}{l}\text { Migraine Disability } \\
\text { Assessment Scale. } \\
\text { (MIDAS) }\end{array}$ & $\begin{array}{l}\text { Average of } \\
\text { Num of } \\
\text { Medication }\end{array}$ \\
\hline $\begin{array}{l}\text { Migraine } \\
\text { without } \\
\text { aura }\end{array}$ & $\begin{array}{l}6.44 \pm \\
0.984\end{array}$ & $\begin{array}{l}14.33 \pm \\
3.199\end{array}$ & $\begin{array}{l}17.03 \pm \\
3.061\end{array}$ & $16.22 \pm 3.735$ & $4.56 \pm 1.49$ \\
\hline $\begin{array}{l}\text { Migraine } \\
\text { without } \\
\text { aura }\end{array}$ & $\begin{array}{l}6.68 \pm \\
1.015\end{array}$ & $\begin{array}{l}12.28 \pm \\
3.845\end{array}$ & $\begin{array}{l}19.93 \pm \\
2.897\end{array}$ & $18.28 \pm .056$ & $4.39 \pm 1.54$ \\
\hline Total & $\begin{array}{l}6.56 \pm \\
0.939\end{array}$ & $\begin{array}{l}13.31 \pm \\
3.161\end{array}$ & $\begin{array}{l}17.93 \pm \\
3.026\end{array}$ & $17.25 \pm 3.981$ & $4.38 \pm 1.57$ \\
\hline$P$ value & 0.75 & 0.92 & 0.39 & 0.61 & 0.92 \\
\hline
\end{tabular}

Table 4-7. The post Hoc test for comparison between the serum CGRP concentration of groups

\begin{tabular}{|c|c|c|c|c|c|c|}
\hline \multirow[t]{2}{*}{ (I) Group } & \multirow[t]{2}{*}{ (J) Group } & \multirow[t]{2}{*}{$\begin{array}{l}\text { Mean Difference } \\
(I-J)\end{array}$} & \multirow[t]{2}{*}{$\begin{array}{l}\text { Std. } \\
\text { Error }\end{array}$} & \multirow[t]{2}{*}{ Sig. } & \multicolumn{2}{|c|}{$\begin{array}{l}95 \% \text { Confidence } \\
\text { Interval }\end{array}$} \\
\hline & & & & & $\begin{array}{l}\text { Lower } \\
\text { Bound }\end{array}$ & $\begin{array}{l}\text { Upper } \\
\text { Bound }\end{array}$ \\
\hline \multirow[t]{2}{*}{$\begin{array}{l}\text { Migraine with } \\
\text { aura }\end{array}$} & $\begin{array}{l}\text { Migraine without } \\
\text { aura }\end{array}$ & .850000 & .792326 & .045 & -2.76266 & 1.06266 \\
\hline & Normal & $6.335278^{*}$ & .792326 & .000 & 4.42262 & 8.24794 \\
\hline \multirow[t]{2}{*}{$\begin{array}{l}\text { Migraine without } \\
\text { aura }\end{array}$} & $\begin{array}{l}\text { Migraine with } \\
\text { aura }\end{array}$ & -.850000 & .792326 & .045 & -1.06266 & 2.76266 \\
\hline & Normal & $7.185278^{*}$ & .792326 & .000 & 5.27262 & 9.09794 \\
\hline \multirow[t]{2}{*}{ Normal } & $\begin{array}{l}\text { Migraine with } \\
\text { aura }\end{array}$ & $-7.185278^{*}$ & .792326 & .000 & -8.24794 & -4.42262 \\
\hline & $\begin{array}{l}\text { Migraine without } \\
\text { aura }\end{array}$ & $-6.335278^{*}$ & .792326 & .000 & -9.09794 & -5.27262 \\
\hline
\end{tabular}




\begin{tabular}{|lll|}
\hline Groups & CGRP level $(\mathrm{pg} / \mathrm{mL})$ & P value \\
\hline Control & $13.97 \pm 2.19$ & 0.000 \\
\cline { 1 - 2 } Migraine without aura & $20.31 \pm 2.68$ & \\
\hline
\end{tabular}

\begin{tabular}{|lll|}
\hline Groups & CGRP level $(\mathrm{pg} / \mathrm{mL})$ & P value \\
\cline { 1 - 2 } Migraine with aura & $21.25 \pm 2.81$ & 0.045 \\
\cline { 1 - 2 } Migraine without aura & $20.31 \pm 2.68$ & \\
\hline
\end{tabular}

\begin{tabular}{|lll|}
\hline Groups & CGRP level $(\mathrm{pg} / \mathrm{mL})$ & P value \\
\hline Migraine with aura & $21.25 \pm 2.81$ & 0.00 \\
\cline { 1 - 2 } Control & $13.97 \pm 2.19$ & \\
\hline
\end{tabular}

